\title{
An Appraisal of Performance of Primary Agricultural Co- operative Societies (PACS) in Nadia District of West Bengal
}

\author{
Pijush Kanti Ghosh ${ }^{1}$, Arabinda Mitra ${ }^{2}$ and Sudipta Sarkar ${ }^{3}$ \\ ${ }^{1}$ Department of Rural Development Studies, University of Kalyani, Kalyani, West Bengal-741235, India \\ ${ }^{2}$ Department of Agricultural Economics, Bidhan Chandra Krishi Viswavidyalaya, Kalyani, West Bengal-741235, India \\ ${ }^{3}$ Department of Rural Development Studies, University of Kalyani, Kalyani, West Bengal-741235, India \\ "Corresponding author: pkgrdsku17@klyuniv.ac.in
}

\begin{abstract}
Primary Agricultural Cooperative Societies (PACS) - the age-long rural institutions were set up mainly focussing credit aspects of farming community. However, with the passage of time PACS have undergone many changes in terms of their modus operandi as well as objectives. Of late they have been mobilizing financial resources from rural households in the form of savings etc. Additionally, they are now promoting Self-Help-Groups (SHGs), particularly women-groups who were untouched earlier. In this paper, attempt is being made to examine performance of PACS in terms of its coverage, inclusion, economic efficiency, social responsibility and prudence in financial management. The study is based on secondary data relating to the period 2007-08 to 2016-17 referring to randomly selected seven PACS of Nadia district, West Bengal. Finally the authors point out to the weaknesses and pitfalls of societies and conclude with some suggestions for strengthening PACS. It has been observed that PACS have broadened their base in terms membership growth and quantum of loan-disbursement. However, they have showed poor performance in recovery and decelerating NPA growth. The reasons for growths in Overdue and NPA need critical observations at ground level. An exhaustive evaluation is needed whether overdue or NPA are owing to growth of wilful or non-wilful defaulters.
\end{abstract}

Keywords: Primary Agricultural Cooperative Societies (PACS), performance evolution

Primary Agricultural Co-operative Societies (PACS) have been playing major roles in rural sector, specifically in agricultural finance frontier for more than a century back. Functioning of PACS has been assessed, modified and monitored at different phases of both pre and post independence periods in India. PACS in Nadia district of West Bengal also witnessed such changes over the years. The authors endeavoured in this paper to make an in depth study of PACS of the district in terms of several indicators based on secondary data covering the period 2007-08 to 2016-17. This study refers to randomly selected seven PACS of Nadia district, West Bengal. In this paper, attempt is being made to examine performance of PACS in terms of its coverage, inclusion, economic efficiency, social responsibility and prudence in financial management.

\section{Methodology}

In this exercise we have chosen thirty eight indicators closely related to the domain of PACSperformance. Data on eighteen (18) indicators for the period under study were directly collected from respective PACS and the rest twenty (20) were computed and derived. List of the indicators could be viewed from Table 1 .

In our analytical framework we have computed exponential growth rates of the respective indicators using the following formula:

$$
A=P_{e}^{r t}
$$

Where, $\mathrm{A}$ is the dependent variable (end value of the indicators, for example no of loannes, total loan, total deposit etc.) 
$r$ is the growth

$P$ is constant

$t$ is the time period

In this paper we have used K-means clustering technique for grouping the selected PACS into homogeneous strata according to growths of indicators. K-means clustering is a statistical tool for grouping the observations into K-clusters in which each observations belongs to the cluster with the nearest mean serving as a prototype of the cluster. The objective of K-means clustering is to minimize total intra cluster variance.

Further, we have classified the PACS into severalclusters according to sub-set of growth indicators as discussed subsequently.

\section{RESULTS AND DISCUSSION}

Table 1 shows growth rates of key-indicators during the period 2007-08 to 2016-17 for respective PACS. However, it is hard to comprehend, compare, contrast and examine the PACS simultaneously with large number of variables. We took the opportunity to oversee performance of these chosen PACS in terms of sub-sets of indicators using $\mathrm{K}$-means clustering.

\section{Coverage and Network}

The following Table 2 shows coverage and network of PACS with respect to seven indicators. PACS have been clustered into three homogeneous groups using K-means clustering process.

The Table 2 witnesses that Mahishbathan is a distinct entity separating from other counter-clusters in terms of coverage. It is seen that growth rates of loanee members including agricultural borrowers were maximum under this unique cluster. Another point of merit to this group has been marked in terms of high growth of agricultural- allied borrowers. Further, this PACS has excelled in fund mobilization or promoting thrift- savings. In contrast, Khishma and Bholadanga Saguna forming the second cluster showed dismal performance in terms of growth of term-depositors. The same table also depicts that number of agricultural allied borrowers have not grown at the same pace as agricultural borrowers grew. The third cluster comprising Haripur, Jitpur, Dharampur and Pipulbaria have shown moderate and impressive growths in the selected indicators. However, this cluster exhibited high growth rate in the number of agricultural allied loanees.

\section{Diversification Portfolio of PACS-loans}

Table 3 and Table 4 examine the growth-pattern of loan disbursement in between agricultural and agricultural allied sector. Apart, this table also witnesses loans disbursed to the SHGs. The selected PACS have been classified into three groups. Referring to the Table 3, we find that Haripur has excelled in agricultural allied sector.

However, it showed negative figure in loan disbursement to the SHGs. The same table also shows high growth rates in all indices in case of the third cluster comprising Pipulbaria, Dharampur and Mahishbathan. Further cluster-2 showed positive growths in the selected variables. However growth in allied agricultural sector lagged far behind agricultural sector in this cluster.

Now coming to the Table 4, we observe poor performance of Bholadanga Saguna and Khishma PACS in terms of growth in per capita loan disbursement both in agriculture and agriculturalallied sector. Growth in SHG sector is positive but with little value in this group. The cluster-2 under this sub-category has figured high growth in per capita loan disbursement but displayed negative trend in agricultural allied sector. This cluster also showed impressive growth in per capita SHG-loans. This cluster has single membership of Pipulbaria. The third cluster formed by four PACS, viz; Haripur, Jitpur, Dharampur and Mahishbathan showed negative performance in agricultural allied loan per caput. Similar trend has been observed in SHG loan per member in this cluster.

Next, we have attempted to examine the financial prudence of PACS in terms of growth in share capital, total loan disbursed, total deposit along with growths in overdue and NPA (Non Performing Asset). Accordingly PACS have been clustered into three homogeneous groups as shown in Table 5.

\section{Financial Prudence}

Looking at the Table 5, it is observed that cluster-1 in which Haripur is the sole member has shown relatively better prudence in financial matter comparing to the rest PACS. In this cluster impressive 
Table 1: Growth of Key-indicators (in \%) for Selected PACS during the Period of 2007-08 to 20016-17

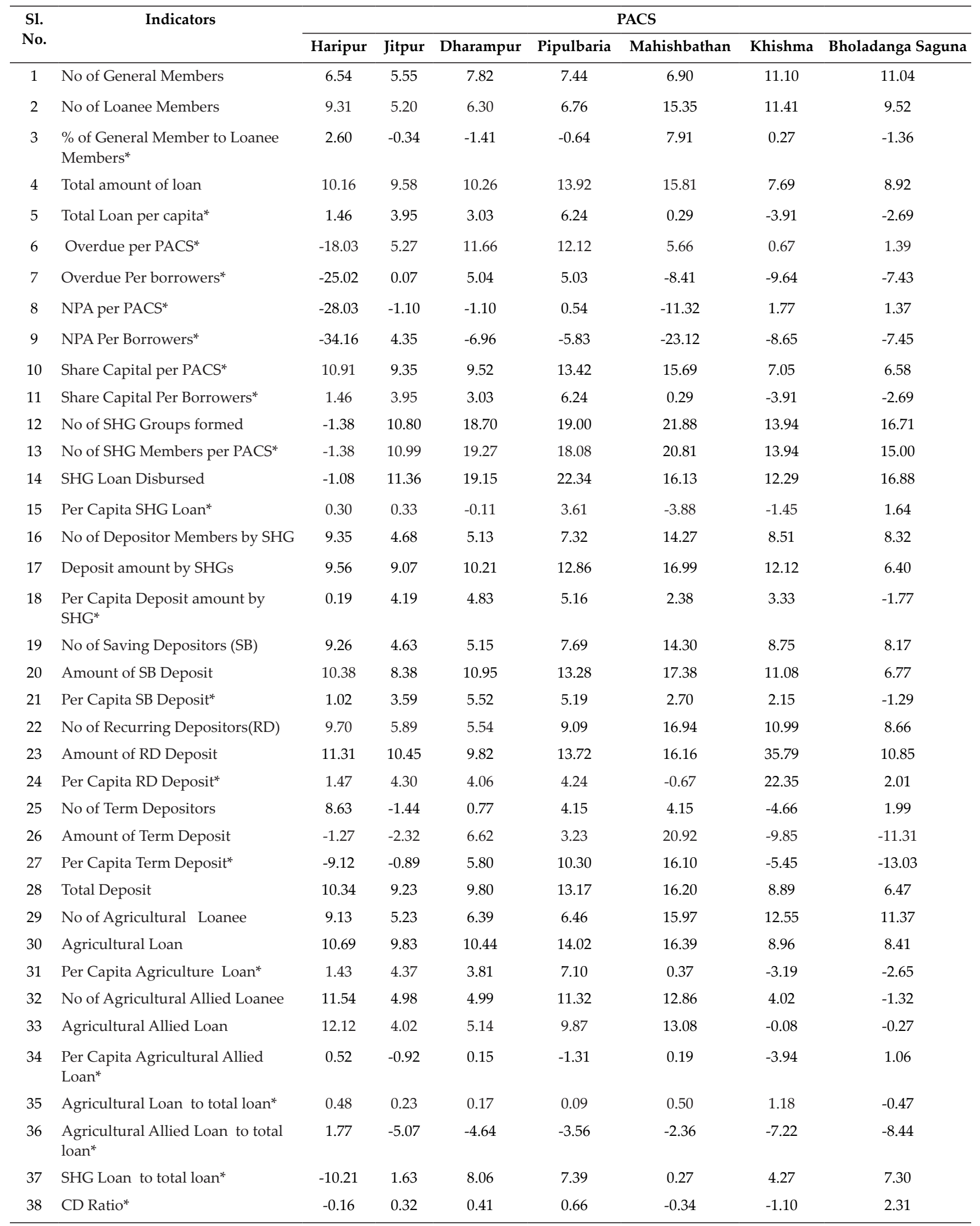

$\left({ }^{*}\right.$ Computed $)$ 
Table 2: Cluster Centres Showing Growth -rate of Selected Indicators

\begin{tabular}{cccc}
\hline Indicators & \multicolumn{3}{c}{ Cluster } \\
\cline { 2 - 4 } & $\mathbf{1}$ & $\mathbf{2}$ & $\mathbf{3}$ \\
\hline No of General Members & 6.90 & 11.07 & 6.84 \\
No of Loanee Members & 15.35 & 10.46 & 6.89 \\
No of Agriculture Loanee & 15.97 & 1.96 & 6.80 \\
No of Agriculture Allied Loanee & 12.87 & 8.46 & 9.21 \\
No of SB Depositors & 14.30 & 9.82 & 7.55 \\
No of RD Depositors & 16.94 & -1.33 & 3.02 \\
No of Term Depositors & 4.15 & & \\
\hline
\end{tabular}

(Cluster-1: Mahishbathan; Cluster-2: Khishma and Bholadanga Saguna and Cluster-3:Haripur, Jitpur, Dharampur and Pipulbaria).

Table 3: Cluster Centres Showing Diversification of Loans in terms of Growth

\begin{tabular}{|c|c|c|c|}
\hline \multirow[t]{2}{*}{ Indicators } & \multicolumn{3}{|c|}{ Cluster } \\
\hline & 1 & 2 & 3 \\
\hline Agricultural Loan disbursed & 10.69 & 9.07 & 13.62 \\
\hline SHG Loan disbursed & -1.08 & 13.51 & 19.20 \\
\hline Total Loan disbursed & 10.16 & 8.73 & 13.33 \\
\hline
\end{tabular}

(Cluster 1: Haripur; Cluster 2: Jitpur, Khishma and Bholadanga Saguna and Cluster 3: Dharampur, Pipulbaria and Mahishbathan).

Table 4: Cluster Centres Showing Growth of per caput Diverse Loans

\begin{tabular}{|c|c|c|c|}
\hline \multirow[t]{2}{*}{ Indicators } & \multicolumn{3}{|c|}{ Cluster } \\
\hline & 1 & 2 & 3 \\
\hline Per Capita Agricultural Loan disbursed & -2.92 & 7.10 & 2.50 \\
\hline Per Capita SHG Loan disbursed & 0.09 & 3.60 & -0.84 \\
\hline Per Capita total Loan disbursed & -3.30 & 6.24 & 2.18 \\
\hline
\end{tabular}

(Cluster 1: Khishma and Bholadanga Saguna, Cluster 2: Pipulbaria and Cluster 3: Haripur, Jitpur, Dharampur and Mahishbathan).

Table 5: Cluster Centres Showing Growth of Loans Overdue, NPA, Share capital, Total Loan Disbursed and Total Deposit

\begin{tabular}{|c|c|c|c|}
\hline \multirow[t]{2}{*}{ Indicators } & \multicolumn{3}{|c|}{ Cluster } \\
\hline & 1 & 2 & 3 \\
\hline Overdue per PACS & -18.03 & 4.75 & 8.89 \\
\hline Share Capital per PACS & 10.91 & 8.12 & 14.55 \\
\hline Total Loan disbursed per PACS & 10.16 & 9.11 & 14.86 \\
\hline
\end{tabular}

(Cluster 1: Haripur; Cluster 2: Jitpur, Dharampur, Khishma and Bholadanga Saguna. and Cluster 3: Pipulbaria and Mahishbathan).

negative trend in overdue- and NPA have been recorded. These two indicators obviously indicate excellence in financial management. Growths of share capital, total deposit are impressive for Haripur PACS. The second cluster has been suffering from the perennial problems of overdue and NPA over the years under study. Alarming growth of overdue has been evidenced in cluster -3 comprising Pipulbaria and Mahishbathan. The bright aspect of this cluster has been of negative growth in NPA. This cluster showed highest growths in share capital, loan disbursement and deposit mobilization comparing to other clusters. 
Table 6: Mean Credit-Deposit (CD) Ratio across PACS at two different periods

\begin{tabular}{cccc}
\hline PACS & $\begin{array}{c}\text { 2007-08 to 2010-11 Average CD } \\
\text { Ratio }\end{array}$ & $\begin{array}{c}\text { 2011-12 to 2016-17 Average } \\
\text { CD Ratio }\end{array}$ & $\begin{array}{c}\text { 2007-08 to 2016-17 Average } \\
\text { CD Ratio }\end{array}$ \\
\hline Haripur & 62.17 & 61.67 & 61.92 \\
Jitpur & 66.19 & 66.70 & 66.44 \\
Dharampur & 62.92 & 64.51 & 63.72 \\
Pipulbaria & 61.48 & 64.44 & 62.96 \\
Mahishbathan & 88.51 & 88.44 & 88.47 \\
Khishma & 79.73 & 73.11 & 76.42 \\
Bholadanga Saguna & 72.22 & 80.25 & 76.24 \\
\hline
\end{tabular}

Table 7: Cluster Centres Showing Growth of CD Ratio, Overdue and NPA during 2007-08 to 2016-17

\begin{tabular}{cccc}
\hline Indicators & \multicolumn{3}{c}{ Cluster } \\
\cline { 2 - 4 } & $\mathbf{1}$ & $\mathbf{2}$ & $\mathbf{3}$ \\
\hline Growth of Credit-Deposit (CD) Ratio & -0.16 & -0.33 & 0.51 \\
Growth of Overdue & -18.03 & 5.65 & 6.22 \\
Growth of NPA & -28.02 & -11.32 & 0.29 \\
\hline
\end{tabular}

(Cluster1: Haripur; Cluster 2: Mahishbathan and Cluster 3: Jitpur, Dharampur, Khishma, Pipulbaria Ltd, Bholadanga Saguna).

Table 8: Cluster Centres Showing Growth of SHG

\begin{tabular}{cccc}
\hline Indicators & \multicolumn{3}{c}{ Cluster } \\
\cline { 3 - 4 } & $\mathbf{1}$ & $\mathbf{2}$ & $\mathbf{3}$ \\
\hline No of SHG Group & -1.38 & 13.82 & 19.86 \\
No of SHG Members & -1.38 & 13.31 & 19.39 \\
\hline
\end{tabular}

(Cluster 1: Haripur, Cluster 2: Jitpur, Khishma and Bholadanga Saguna. and Cluster 3: Dharampur, Pipulbaria and Mahishbathan).

Table 6 shows mean CD ratio of respective PACS over two segments of time period as well as the entire period under study. The table shows that CD ratios were more than $60 \%$ in both the periods. Further, Mahishbathan displayed more than $88 \%$ $\mathrm{CD}$ ratio during the two phases. Bholadanga Saguna also recorded more than $80 \% \mathrm{CD}$ ratio during 2011-12 to 2016-17. A slight fall in the CD ratio was observed in case of Khishma but the mean CD ratio stood at $73.11 \%$ in the later period. High CD ratio represents PACS aggressiveness in credit disbursement relative to total deposit. The merit of high CD ratios irrespective of PACS scanned through the growths of overdue and NPA as shown in Table 7.

It is clear from above table that Haripur is the single PACS showing negative growths in CD ratio, overdue and NPA over the period under study.
Growth of $\mathrm{CD}$ ratio along with high positive growth in overdue has been evidenced in cluster-3. This particular cluster also witnessed positive growth of NPA. In contrast, Mahishbathan showed negative growth of $C D$ ratio with positive trend of overdue. Mahishbathan also witnessed decreasing growths in NPA. Overall impression of this table is of PACS poor performance in financial management.

\section{Social Impact}

Social impact of PACS has been measured in terms growths in SHGs formation and members' enrolment under respective PACS. Haripur PACS has showed poor outcome in above contexts as seen in Table 8. All other PACS have shown positive trend in shouldering social responsibility. Amongst the PACS Dharampur, Pipulbaria and Mahishbathan are leading PACS showing impressive social impact. 


\section{CONCLUSION}

Summarizing above discussions it could be said that PACS have broadened their base in terms membership growth and quantum of loandisbursement. However, they have showed poor performance in recovery and decelerating NPA growth.

The reasons for growths in Overdue and NPA need critical observations at ground level. An exhaustive evaluation is needed whether overdue or NPA are owing to growth of wilful or non-wilful defaulters. For non-wilful defaulters PACS need to be pragmatic in loan disbursement. Credit should commensurate with the production and creating surplus at farmers' hands. PACS will have to provide skills along with necessary inputs at time and mobilize farmers in adopting high value package practises. Supervision of credit and monitoring credit periodically would definitely curb the magnitude of overdue and NPA and ensure better performance in PACS.

\section{REFERENCES}

Amarjothi, P. 2014. A Study on Financial Performance of Primary Agricultural Co-Operative Bank in Kottagudi at Madurai District, International Journal of Commerce, Business and Management (IJCBM), 3(2): 321-331.

Charkravarthy, P.K. 1983. Problems of Cooperative Development in India, New Delhi: S. Chand and Company Ltd., pp. 45.

Desai, V. 1983. A Study of Rural Economics - A Systems Approach, Bombay: Himalaya Publishing House, pp. 516-517.

Dhankar, B.L. 1971. A Co-operative Primary Bank promise and performance. Indian Co-operative Review, 9(1): 61-80.

Kainth, G.S. 1998. India's Rural Co-operatives, New Delhi: Regency Publications, pp.145, 147, 215, 230.

Mathur, B.S. 1980. Co-operation in India, Agra: Sahitya Bhavan, pp. 59-64.

Mariyanthan, A.A. 1973. Primary Agricultural Credit Societies their progress, performance and problems. Indian Cooperative Review, 11(1): 53-73.
Misra, B. 1997. Co-operative Movement in India, New Delhi: A.P.H. Publishing Corporation, pp.1 81.

Ramesh, B. and Patil, M.R. 1999. Towards measuring cooperatives performance, Co-operative Perspective, 33(4): 43-50.

Sathyanarayana, E. 1984. Need to Reactive Credit Cooperatives, Kurukshetra, XXXII(8): 16-19.

Satya Sai, K.J.S, Vekateswarlu, U.V. and Seetharaman, S. 1987. Overdue Pattern of Agricultural Credit-A Study in Progressive Block of West Godavari District A.P, Indian Co-operative Review, XXIV: 296-305.

Sharma, S.K. 2014. Performance of Primary Agriculture Cooperative Societies in Himachal Pradesh, Global Journal of Multidisciplinary Studies, 3: 59-67.

Sinha, S.K. 1998. Rural Credit and Cooperatives in India, New Delhi; Suneja Publishers, pp. 79.

Sinha, B.P. 1991. Glimpses of Co-operation in the Indian Context. New Delhi: Himalaya Publications, pp. 14-15.

Singh, S. and Kaur, M. 2000. Performance of Agriculture Co-operative Service Societies in Punjab: An Appraisal, Co-operative Perspective, 34(4): 16-25.

Sivaprakasam, P. 1996. Defaulters of Agricultural Credit Co-operative: A Study with Special Reference to the Short-term Agricultural Credit, Indian Co-operative Review, XXXIII(3): 238-243.

Tyagi, R.B. 1967. Recent Trends in the Co-operative Movement India. New Delhi: Asia Publications, pp. 15.

Uddin, S. and Rahman, M. 1983. Co-operative Sector in India - After independence, New Delhi: S. Chand and Company Ltd, pp. 40.

Vaikunthe, L.D, 1991. Agricultural Co-operative Credit Utilization and Recovery Performance A Case Study of K.C.C. Banck, Dharwad, Indian Co-operative Review, XXIX(1): 39-46.

Viswanath, A.R. 1999. An Analysis of the Performance of Agricultural Credit Co-operatives and their Over dues Problem on India, Indian Co-operative Review, XXVI (3): 271-276. 